\title{
HIF-1 $\alpha$ silencing suppresses growth of lung adenocarcinoma A549 cells through induction of apoptosis
}

\author{
HONG-YING LIAO ${ }^{1}$, GUI-PING WANG ${ }^{2}$, SHAO-HONG HUANG ${ }^{1}$, YUN LI ${ }^{1}$, SONG-WANG CAI ${ }^{1}$, \\ JIAN ZHANG ${ }^{1}$, HUI-GUO CHEN ${ }^{1}$ and WEI-BIN WU ${ }^{1}$ \\ ${ }^{1}$ Department of Thoracic Surgery, Clinical Research Center of Chest Tumor, Third Affiliated Hospital, \\ Sun Yat-sen University, Guangzhou, Guangdong 510630; ${ }^{2}$ Department of Pharmacy, Health College, \\ Guangzhou Medical University, Guangzhou, Guangdong 510180, P.R. China
}

Received June 14, 2013; Accepted January 6, 2014

DOI: $10.3892 / \mathrm{mmr} .2014 .1910$

\begin{abstract}
Lung adenocarcinoma (AC) is one of the most deadly malignancies. The disease has a low five-year survival rate; therefore, the identification of novel therapeutic agents is required. This study aimed to investigate the effect of small interfering RNA (siRNA) targeting hypoxia-inducible factor $1 \alpha(\mathrm{HIF}-1 \alpha)$ on the growth of AC A549 cells. A549 cells were transfected with various concentrations of HIF-1 $\alpha$ or control siRNA, and the effect on HIF-1 $\alpha$ expression was analyzed using quantitative polymerase chain reaction and western blot analysis. The effects of HIF-1 $\alpha$ siRNA on growth inhibition and apoptosis were then assessed using standard methods. HIF-1 $\alpha$ siRNA treatment significantly reduced HIF-1 $\alpha$ mRNA and protein expression in A549 cells. Furthermore, the downregulation of HIF-1 $\alpha$ expression inhibited the growth of A549 cells and induced apoptosis of A549 cells by upregulating caspase-3 expression. The present in vitro study demonstrates that the downregulation of HIF-1 $\alpha$ is capable of suppressing AC A549 cell growth, through the induction of apoptosis. This suggests that HIF-1 $\alpha$ inhibition may represent a promising strategy for the treatment of AC.
\end{abstract}

\section{Introduction}

Lung cancer is the most common form of cancer, and the leading cause of cancer-induced mortality in humans. Non-small cell lung cancer (NSCLC) accounts for $80 \%$ of all lung cancer diagnoses, with lung adenocarcinoma (AC) representing one of the most predominant histological types of NSCLC and accounting for $20-30 \%$ of all cases $(1,2)$. The majority of patients with NSCLC are diagnosed in the late

Correspondence to: Dr Hong-Ying Liao, Department of Thoracic Surgery, Clinical Research Center of Chest Tumor, Third Affiliated Hospital, Sun Yat-sen University, 600 Tian He Road, Guangzhou, Guangdong 510630, P.R. China

E-mail: hylmed1996@126.com

Key words: RNA interference, HIF-1 $\alpha$, target therapy, lung adenocarcinoma stage, when the tumor has become unresectable; therefore, chemotherapy remains the first treatment plan for advanced NSCLC. Clinically, cisplatin (DDP) in combination with other antitumor agents, including paclitaxel, gemcitabine and vinorelbine, is the first-line therapeutic strategy for treatment of advanced NSCLC (3). Recently, certain small molecule agents have shown favorable results for lung AC treatment; however, improvements are often insignificant with regard to the extension of the life of the patient with NSCLC (4). For example, certain patients with the epidermal growth factor receptor (EGFR) mutation benefit from gefitinib and erlotinib, whilst others with the echinoderm microtubule-associated protein-like 4-anaplastic lymphoma kinase (EML4-ALK) mutation benefit from crizotinib. However, numerous patients remain who are unable to benefit from such targeted therapy, due to the lack of effective gene-specific agents (4-6). Therefore, the identification of new and effective therapeutic agents for the treatment of lung $\mathrm{AC}$ is required.

Hypoxia-inducible factor 1 (HIF-1) is a heterodimeric transcription factor consisting of a constitutively expressed $\beta$-subunit and an oxygen-regulated $\alpha$-subunit, and has a critical role in the adaptive response to hypoxic environments. HIF-1 regulates $>60$ downstream genes involved in energy metabolism, angiogenesis, tumor growth and progression, metastatic spread and apoptosis (7). Overexpression of HIF-1 $\alpha$ has been detected in $>70 \%$ of solid tumors. While upregulation or activation of HIF-1 $\alpha$ promotes tumor growth, downregulation or loss of HIF-1 $\alpha$ activity has been demonstrated to markedly decrease tumor growth, vascularization and energy metabolism (8-11). The suppression of HIF-1 $\alpha$ expression by RNA interference (RNAi) has been shown to be an effective method of cancer therapy (12).

Evidence suggests that HIF-1 $\alpha$ is widely expressed in NSCLC tissue, and is associated with the expression of numerous biological factors involved in NSCLC pathogenesis, including vascular endothelial growth factor, platelet-derived endothelial cell growth factor and basic fibroblastic growth factor (8,11,13-16). In addition, high levels of HIF-1 $\alpha$ are also associated with a poor prognosis, independent of routinely used clinicopathological variables. At present, several small molecule inhibitors of HIF-1 $\alpha$ have been identified and are awaiting clinical trial (7). However, none of the presently 
available inhibitors exclusively target HIF-1 $\alpha$. To address the potential of small interfering RNA (siRNA) targeting HIF1 $\alpha$ for the treatment of AC, the effect of siRNA targeting HIF-1 $\alpha$ on the growth of AC A549 cells was investigated. The results showed that siRNA targeting HIF-1 $\alpha$ significantly inhibited the expression of HIF-1 $\alpha$ in A549 cells. The results also indicated that silencing of HIF-1 $\alpha$ was capable of suppressing the growth of AC A549 cells through induction of apoptosis.

\section{Materials and methods}

Cell culture. Human lung AC A549 cells were purchased from the Shanghai Cell Bank of Chinese Academy of Science (Shanghai, China), and cultured in RPMI-1640 (Gibco-BRL, Grand Island, NY, USA) containing 15\% calf serum, $100 \mathrm{U} / \mathrm{ml}$ penicillin and $100 \mathrm{mg} / 1$ streptomycin at $37^{\circ} \mathrm{C}$ in a humidified atmosphere containing $5 \% \mathrm{CO}_{2}$. For hypoxic treatment, cells were cultured in a modular incubator chamber $\left(\right.$ Forma $^{\circledR}$, Thermo Fisher Scientific, Waltham, MA, USA) that was infused with $2 \% \mathrm{O}_{2}, 5 \% \mathrm{CO}_{2}$, and $93 \% \mathrm{~N}_{2}$.

RNAi treatment. siRNA targeting HIF-1 $\alpha$ was designed and validated by Boya Bio-engineering Company (Shanghai, China) (17). The antisense sequence of siRNA targeting HIF-1 $\alpha$ was 5'-AGTTCACCTGAGCCTAATA-3', and the control sequence was 5'-CTTAGCCTTCGAATGATCT-3'. Gene silencing was performed via transfection with the HIF-1 $\alpha$ siRNA $(25,50$ and $100 \mathrm{nM})$ and control sequences. siRNA was transfected into A549 cells using Lipofectamine 2000, according to the manufacturer's instructions (Invitrogen Life Technologies, Carlsbad, CA, USA). Cells were pretreated with siRNA for $4 \mathrm{~h}$ at $37^{\circ} \mathrm{C}$ under normoxic conditions. Cells were then transferred to hypoxic conditions or maintained in a normoxic environment for the indicated durations.

Quantitative polymerase chain reaction ( $q P C R)$ analysis. A549 cells were washed twice with ice-cold phosphate-buffered saline (PBS) and harvested using a cell scraper. Total RNA was isolated using TRIzol reagent, and cDNA was synthesized according to the manufacturer's instructions (Invitrogen Life Technologies). qPCR was performed using a standard SYBR-Green PCR Master Mix (Toyobo Corp, Osaka, Japan) (18), and PCR-specific amplification was conducted in a 7900HT Fast Real-Time PCR System from Applied Biosystems (Forster City, CA, USA). The primers for HIF-1 $\alpha$ and glyceraldehyde-3-phosphate dehydrogenase (GAPDH; used as an internal normalization control) were as follows: HIF-1 $\alpha$, 5'-CAGCAACCAGGTGACCGTG-3' (forward) and 5'-TGCTGCCTTGTATGGGAGCATT-3' (reverse); GAPDH, 5'-CGGAGTCAACGGATTTGGTGGTAT-3' (forward) and 5'-AGCCTTCTCCATGGTGGTGAAGAC-3' (reverse).

Western blot analysis. Protein extracts were equally loaded on a $10 \%$ sodium dodecyl sulfate-polyacrylamide gel, electrophoresed and transferred to a nitrocellulose membrane. The blots were stained with $0.2 \%$ Ponceau S red to ensure equal protein loading. Following blocking with 5\% non-fat milk in PBS, membranes were then probed with primary antibodies against HIF- $1 \alpha$ or caspase-3 (Invitrogen Life Technologies) at $4^{\circ} \mathrm{C}$ overnight. Membranes were then probed with an alkaline phosphatase-linked secondary antibody (Santa Cruz Biotechnology, Inc., Santa Cruz, CA, USA) for $1 \mathrm{~h}$ at $37^{\circ} \mathrm{C}$. Signals were detected using a chemiluminescence Phototope ${ }^{\circledR}$-horseradish peroxidase (HRP) kit, according to the manufacturer's instructions (Cell Signaling Technology Inc., Beverly, MA, USA). Where necessary, $\beta$-actin (Invitrogen Life Technologies) was used as an internal control.

MTT assay. To evaluate the effect of HIF-1 $\alpha$ siRNA on lung AC cells, the MTT assay was performed as previously described $(18,19)$. Cells were grown in monolayer culture to $60 \%$ confluency, harvested using Trypsin and plated at a density of $4 \times 10^{4}$ cells/well into separate wells of a 96-well plate (Costar; Corning Inc., Corning, NY, USA). Incubation was continued in $1 \% \mathrm{O}_{2}$ (hypoxia) conditions. Following incubation for the indicated times, $20 \mu \mathrm{l} 5 \mathrm{mg} / \mathrm{ml}$ MTT (Sigma, St. Louis, MO, USA) solution in PBS was added to each well for an additional $4 \mathrm{~h}$. Subsequently, the supernatant was discarded and $150 \mu \mathrm{l}$ dimethylsulfoxide (DMSO) was added to each well. Following MTT incubation, the absorbance of the samples was determined using a microplate reader at $490 \mathrm{~nm}$ (Sunrise ${ }^{\mathrm{TM}}$; Tecan Group Ltd., Männedorf, Switzerland). All experiments were performed at least three times for each experimental condition.

Annexin-V assay. The Annexin-V assay was performed using the Annexin V-fluorescein isothiocyanate (FITC) Apoptosis Detection kit according to the manufacturer's instructions (Becton Dickinson, San Diego, CA, USA) (17). Briefly, $2 \times 10^{5}$ cells were collected, washed twice with cold PBS, suspended in $100 \mu \mathrm{l}$ binding buffer, and incubated with Annexin V-FITC at room temperature for $10 \mathrm{~min}$. Subsequently, $5 \mu \mathrm{l}$ propidium iodide (PI, $20 \mu \mathrm{g} / \mathrm{ml}$ ) was added and cells were incubated away from the light at room temperature for $5 \mathrm{~min}$. Cells were then directly analyzed by FACScan $^{\mathrm{TM}}$ (Beckton Dickinson) and evaluated using the Cell Quest program (Becton Dickinson).

Statistical analysis. The data were analyzed using the SPSS 15.0 software package (SPSS, Inc., Chicago, IL, USA). One-way analysis of variance (ANOVA) followed by post hoc least significant difference (LSD) or Dunnett's tests was performed to determine the significance of the differences in multiple comparisons. A value of $\mathrm{P}<0.05$ was considered to indicate a statistically significant difference.

\section{Results}

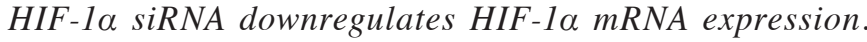
To assess the potential for HIF-1 $\alpha$ siRNA to block HIF-1 $\alpha$ expression, HIF-1 $\alpha$ mRNA expression levels in A549 cells were analyzed using qPCR. Under normoxic conditions, HIF-1 $\alpha$ mRNA was expressed at low levels in A549 cells; however, under hypoxic conditions, HIF-1 $\alpha$ mRNA expression was significantly increased (Fig. 1A). HIF-1 $\alpha$ siRNA significantly inhibited the expression of HIF-1 $\alpha$ mRNA in HIF1 $\alpha$ siRNA-treated cells, $(\mathrm{P}<0.05)$, particularly at concentrations of 50 and $100 \mathrm{nM}$, compared with control cells (Fig. 1B).

HIF-1 $\alpha$ siRNA reduces HIF-1 $\alpha$ protein expression. To investigate the effect of HIF-1 $\alpha$ siRNA on HIF-1 $\alpha$ protein expression, 

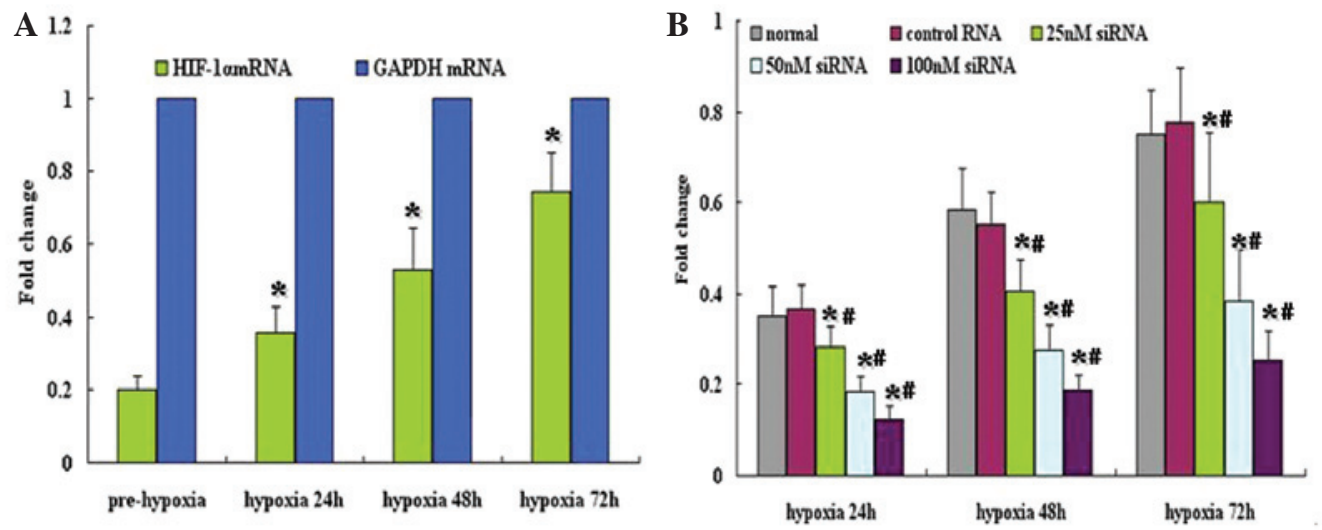

Figure 1. Downregulation of HIF-1 $\alpha$ mRNA in lung adenocarcinoma A549 cells caused by HIF-1 $\alpha$ siRNA. (A) HIF-1 $\alpha$ mRNA expression in A549 cells under normoxia and hypoxia. A549 cells were exposed to hypoxia for 24,48 and $72 \mathrm{~h}$, respectively and HIF-1 $\alpha$ mRNA was detected using quantitative-PCR. GAPDH served as an internal control. (B) HIF-1 $\alpha$ siRNA suppresses expression of HIF-1 $\alpha$ mRNA in A549 cells. Relative HIF-1 $\alpha$ mRNA expression was calculated to assess the ability of indicated agents to suppress HIF-1 $\alpha$ mRNA expression. Each bar represents the mean $\pm \mathrm{SD}(\mathrm{n}=3)$. ${ }^{*} \mathrm{P}<0.05$ vs. normal; ${ }^{*} \mathrm{P}<0.05$ vs. control. HIF-1 $\alpha$, hypoxia-inducible factor $1 \alpha$; siRNA, small interfering RNA; PCR, polymerase chain reaction; GAPDH, glyceraldehyde-3-phosphate dehydrogenase.
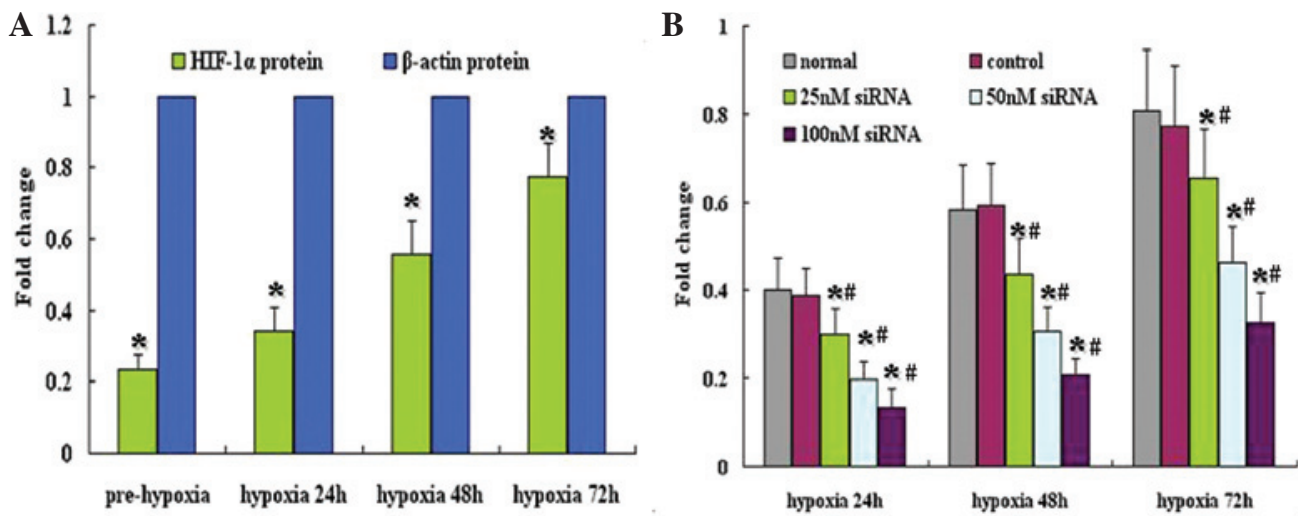

Figure 2. Effect of HIF-1 $\alpha$ siRNA on HIF-1 $\alpha$ protein expression in lung adenocarcinoma A549 cells. Expression of HIF-1 $\alpha$ protein was determined using western blot analysis. (A) HIF-1 $\alpha$ protein expression of A549 cells under normoxia and hypoxia (24, 48 and 72 h). (B) Various concentrations of HIF-1 $\alpha$ siRNA downregulated levels of HIF-1 $\alpha$ protein expression under hypoxic conditions. Each bar represents the mean $\pm \mathrm{SD}(\mathrm{n}=3)$. ${ }^{\mathrm{P}} \mathrm{P}<0.05$ vs. normal; ${ }^{\#} \mathrm{P}<0.05$ vs. control. HIF-1 $\alpha$, hypoxia-inducible factor $1 \alpha$; siRNA, small interfering RNA.

western blot analysis was performed. The results are shown in Fig. 2. Under normoxic conditions, HIF-1 $\alpha$ protein expression in A549 cells was low; however, expression was markedly induced under hypoxia (Fig. 2A). Treatment with control siRNA did not affect HIF-1 $\alpha$ protein expression; however, HIF-1 $\alpha$ siRNA significantly downregulated HIF- $1 \alpha$ protein expression under hypoxic conditions (Fig. 2B).

HIF-1 $\alpha$ siRNA inhibits the growth of A549 cells. HIF-1 $\alpha$ has a critical role in cell growth in a number of tumor cell lines; therefore the effect of HIF-1 $\alpha$ silencing on A549 cell growth was assessed in vitro. As shown in Fig. 3, under hypoxia, HIF-1 $\alpha$ siRNA significantly inhibited growth of A549 cells, particularly at concentrations of 50 and $100 \mathrm{nM}$, compared with control siRNA. Moreover, the suppression of growth in the HIF-1 $\alpha$ siRNA-transfected cells was more efficient under $72 \mathrm{~h}$ hypoxia, compared with $24 \mathrm{~h}$

HIF-1 $\alpha$ siRNA induces apoptosis in A549 cells. Flow cytometry experiments were performed to determine whether the growth inhibitory effect observed in A549 cells treated with

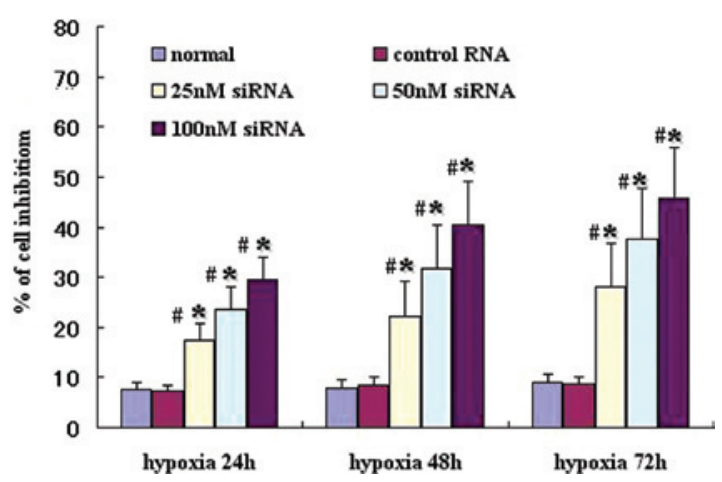

Figure 3. Effect of HIF-1 $\alpha$ siRNA on the proliferation of lung adenocarcinoma A549 cells in vitro. Following exposure to the indicated hypoxic conditions $(24,48,72 \mathrm{~h})$, the inhibition of proliferation by HIF-1 $\alpha$ was assessed using MTT assay. Each bar represents the mean $\pm \mathrm{SD}(\mathrm{n}=3)$. ${ }^{*} \mathrm{P}<0.05$ vs. normal; ${ }^{\#} \mathrm{P}<0.05$ vs. control. HIF- $1 \alpha$, hypoxia-inducible factor $1 \alpha$; siRNA, small interfering RNA.

HIF-1 $\alpha$ siRNA, was associated with apoptosis. Annexin-V and PI staining were used to detect apoptotic cells, including early- $\left(\mathrm{FITC}^{+} / \mathrm{PI}\right)$ and late-stage apoptosis or necrotic cells 

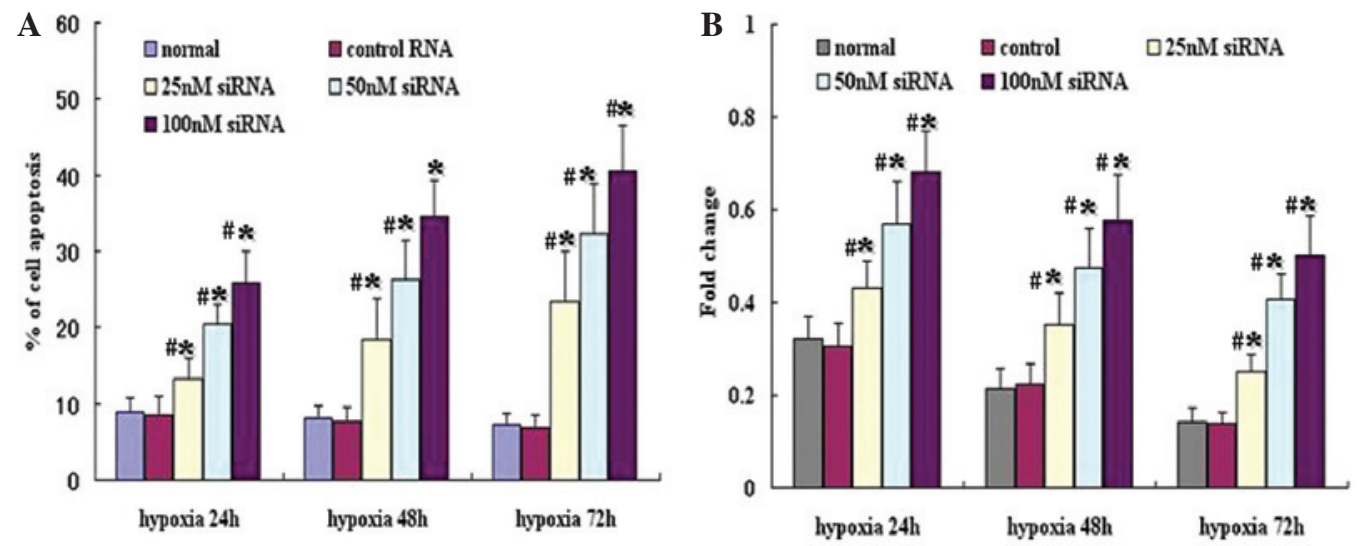

Figure 4. HIF-1 $\alpha$ siRNA induces caspase-dependent apoptosis. (A) Effect of HIF-1 $\alpha$ siRNA on cell apoptosis quantified using Annexin-V/PI detection. A549 cells were transfected with siRNA for $4 \mathrm{~h}$, then exposed to serum starvation under hypoxic conditions for 24,48 and $72 \mathrm{~h}$. Apoptotic cells were detected using fluorescence flow cytometry. (B) HIF-1 $\alpha$ siRNA increases levels of caspase-3 expression under hypoxic conditions. Caspase-3 expression was detected using western blot assay. Each bar represents the mean $\pm \mathrm{SD}(\mathrm{n}=3) .{ }^{*} \mathrm{P}<0.05$ vs. normal; ${ }^{*} \mathrm{P}<0.05$ vs. control. HIF-1 $\alpha$, hypoxia-inducible factor $1 \alpha$; siRNA, small interfering RNA; PI, propidium iodide.

$\left(\mathrm{FITC}^{+} / \mathrm{PI}^{+}\right)$. As shown in Fig. 4A, under hypoxic conditions, HIF-1 $\alpha$ siRNA caused a significant induction of apoptosis in A549 cells compared with the control $(\mathrm{P}<0.05)$, particularly at concentrations of 50 or $100 \mathrm{nM}$.

To analyze the apoptosis induced by HIF-1 $\alpha$ siRNA under hypoxic conditions, levels of caspase-3, a critical indicator of apoptosis, were examined. Under hypoxia, the level of caspase-3 was significantly increased following HIF-1 $\alpha$ siRNA transfection, particularly with 50 or $100 \mathrm{nM}$ of HIF-1 $\alpha$ siRNA (Fig. 4B).

\section{Discussion}

In the majority of types of human cancer, including lung $\mathrm{AC}$, overexpression of HIF-1 promotes cell proliferation, apoptosis and metastasis $(15,16,20,21)$. In the present study, the results indicated that silencing HIF1- $\alpha$ with siRNA may represent a therapeutically beneficial strategy for treatment of AC. Hypoxia markedly increased HIF-1 $\alpha$ mRNA and protein expression in A549 cells; however, silencing HIF-1 $\alpha$ with siRNA effectively inhibited HIF-1 $\alpha$ mRNA and protein expression. Furthermore, under hypoxia, HIF-1 $\alpha$ siRNA significantly inhibited A549 cell growth, and promoted apoptosis through upregulation of caspase-3 expression.

Tissue hypoxia is a fundamental characteristic of solid tumors, including types of lung cancer, and promotes biological processes involved in tumor progression. Based on the central role of HIF- $1 \alpha$ in the adaptive response to hypoxia, targeting HIF-1 $\alpha$ may serve as a potential anticancer strategy for the clinic (7). Consistent with results from previous studies, the present results demonstrated that in A549 cells, HIF-1 $\alpha$ mRNA and protein were expressed at low levels under normoxic conditions; however, mRNA and protein levels increased markedly under hypoxia $(13,15)$. Previous evidence has suggested that HIF-1 $\alpha$ is important in the regulation of cell growth and development, as well as invasion of AC $(11,16)$. It was therefore hypothesized that the downregulation of HIF-1 $\alpha$ was likely to lead to growth inhibition of AC. At present, a number of small molecule inhibitors, such as 17-AAG, temsirolimus and rapamycin, have been demonstrated to decrease
HIF-1 $\alpha$ expression; however, none of these drugs have been shown to directly and specifically target HIF-1 $\alpha$ (7). In the present study, it was observed that HIF-1 $\alpha$ silencing by siRNA not only significantly inhibited the expression of HIF-1 $\alpha$ mRNA and protein, but also effectively suppressed the proliferation of AC cells under hypoxic conditions.

Apoptosis is important in the regulation of tumor cell growth, metastasis and invasion. Numerous studies have reported that HIF-1 $\alpha$ regulates cancer cell growth and apoptosis; however, HIF-1 $\alpha$ possesses dual functions in mediating apoptosis of tumor cells, i.e, anti- and pro-apoptotic function $(13,14,22,23)$. The overall effect of HIF-1 $\alpha$ on cell apoptosis remains incompletely understood, but may depend on tumor microenvironment, particularly hypoxia (21). As a fast-growing cancer, AC often exhibits a hypoxic microenvironment and metabolic disturbance. Evidence suggests that HIF-1 $\alpha$ is widely expressed in NSCLC tissue, including lung AC. The present study demonstrated that, under hypoxia, silencing HIF-1 $\alpha$ using siRNA induced A549 cell apoptosis in vitro, in a caspase-dependent manner. Caspases are crucial mediators of programmed cell death (apoptosis), with caspase-3 representing a frequently activated death protease that catalyzes the specific cleavage of key cellular proteins, and is required for certain hallmarks of apoptosis (24). In AC cells, it was observed in the present study that HIF-1 $\alpha$ siRNA effectively upregulated the level of caspase-3 expression under hypoxic conditions, in line with the increase in A549 cell apoptosis induced by HIF-1 $\alpha$ siRNA.

In conclusion, the present study showed that siRNA technology may be used to specifically inhibit HIF-1 $\alpha$ expression in AC cell lines. Silencing of HIF-1 $\alpha$ not only induced apoptosis in AC A549 cells, but also suppressed growth of AC. However, achieving the specific efficiency of HIF-1 $\alpha$ siRNA in vivo remains a challenge. There is a requirement for further in-depth studies and trials to verify the antitumor activity of HIF-1 $\alpha$ siRNA.

\section{Acknowledgements}

This study was supported by the Science and Technology Foundation of Guangdong Province (no. 2008B030301315). 


\section{References}

1. Kadara H, Kabbout M and Wistuba II: Pulmonary adenocarcinoma: a renewed entity in 2011. Respirology 17: 50-65, 2012.

2. Travis WD, Brambilla E, Noguchi M, et al; American Thoracic Society: International Association for the Study of Lung Cancer/American Thoracic Society/European Respiratory Society: international multidisciplinary classification of lung adenocarcinoma: executive summary. Proc Am Thorac Soc 8: 381-385, 2011

3. Hodkinson PS and Sethi T: Advances in the prevention and treatment of lung cancer. J R Coll Physicians Edinb 41: 142-149, 2011.

4. Mitsudomi T and Yatabe Y: Mutations of the epidermal growth factor receptor gene and related genes as determinants of epidermal growth factor receptor tyrosine kinase inhibitors sensitivity in lung cancer. Cancer Sci 98: 1817-1824, 2007.

5. de Mello RA, Marques DS, Medeiros R and Araújo AM Epidermal growth factor receptor and K-Ras in non-small cell lung cancer-molecular pathways involved and targeted therapies. World J Clin Oncol 2: 367-376, 2011.

6. Moran C: Importance of molecular features of non-small cell lung cancer for choice of treatment. Am J Pathol 178: 1940-1948, 2011.

7. Patiar S and Harris AL: Role of hypoxia-inducible factor-1alpha as a cancer therapy target. Endocr Relat Cancer 13 (Suppl 1): S61-S75, 2006

8. Savai R, Schermuly RT, Voswinckel R, et al: HIF-1 $\alpha$ attenuates tumor growth in spite of augmented vascularization in an A549 adenocarcinoma mouse model. Int J Oncol 27: 393-400, 2005.

9. Scortegagna M, Martin RJ, Kladney RD, Neumann RG and Arbeit JM: Hypoxia-inducible factor-1alpha suppresses squamous carcinogenic progression and epithelial-mesenchymal transition. Cancer Res 69: 2638-2646, 2009.

10. Sinha I, Null K, Wolter W, et al: Methylseleninic acid downregulates hypoxia-inducible factor-1 $\alpha$ in invasive prostate cancer. Int J Cancer 130: 1430-1439, 2012.

11. Wan J, Chai $\mathrm{H}, \mathrm{Yu} \mathrm{Z}$, et al: HIF-1 $\alpha$ effects on angiogenic potential in human small cell lung carcinoma. J Exp Clin Cancer Res 30: 77, 2011.
12. Hannon GJ: RNA interference. Nature 418: 244-251, 2002.

13. Volm M and Koomägi R: Hypoxia-inducible factor (HIF-1) and its relationship to apoptosis and proliferation in lung cancer. Anticancer Res 20: 1527-1533, 2000.

14. Swinson DE, Jones JL, Cox G, et al: Hypoxia-inducible factor-1 alpha in non small cell lung cancer: relation to growth factor, protease and apoptosis pathways. Int J Cancer 111: 43-50, 2004

15. Shyu KG, Hsu FL, Wang MJ, Wang BW and Lin S: Hypoxia-inducible factor lalpha regulates lung adenocarcinoma cell invasion. Exp Cell Res 313: 1181-1191, 2007.

16. Luo F, Liu X, Yan N, et al: Hypoxia-inducible transcription factor-1alpha promotes hypoxia-induced A549 apoptosis via a mechanism that involves the glycolysis pathway. BMC Cancer 6: 26, 2006.

17. Liao HY, Wang GP, Gu LJ, et al: HIF-1 $\alpha$ siRNA and cisplatin in combination suppress tumor growth in a nude mice model of esophageal squamous cell carcinoma. Asian Pac J Cancer Prev 13: 473-477, 2012.

18. Wang $\mathrm{G}$, Ye $\mathrm{Y}$, Yang $\mathrm{X}$, Liao $\mathrm{H}$, Zhao $\mathrm{C}$ and Liang $\mathrm{S}$ : Expression-based in silico screening of candidate therapeutic compounds for lung adenocarcinoma. PLoS One 6: e14573, 2011.

19. Xu K, Ding Q, Fang Z, et al: Silencing of HIF-1alpha suppresses tumorigenicity of renal cell carcinoma through induction of apoptosis. Cancer Gene Ther 17: 212-222, 2010.

20. Kurokawa T, Miyamoto M, Kato K, et al: Overexpression of hypoxia-inducible-factor 1alpha(HIF-1alpha) in oesophageal squamous cell carcinoma correlates with lymph node metastasis and pathologic stage. Br J Cancer 89: 1042-1047, 2003

21. Theodoropoulos GE, Lazaris AC, Theodoropoulos VE, et al: Hypoxia, angiogenesis and apoptosis markers in locally advanced rectal cancer. Int J Colorectal Dis 21: 248-257, 2006.

22. Flamant L, Notte A, Ninane N, Raes M and Michiels C: Anti-apoptotic role of HIF-1 and AP-1 in paclitaxel exposed breast cancer cells under hypoxia. Mol Cancer 9: 191, 2010.

23. Yook YJ, Seo YJ, Kang HJ, et al: Induction of hypoxia-inducible factor-1 $\alpha$ inhibits drug-induced apoptosis in the human leukemic cell line HL-60. Korean J Hematol 45: 158-163, 2010.

24. Olsson M and Zhivotovsky B: Caspases and cancer. Cell Death Differ 18: 1441-1449, 2011. 